\title{
Educación ciudadana y convivencia democrática. \\ Entre las políticas educativas, \\ la alfabetización escolar y el \\ aprendizaje en la ciudad
}

$\begin{array}{ll}\text { Citizenship } & \text { Educação cidadã } \\ \text { Education and } & \text { e convivência } \\ \text { Democratic } & \text { Eemocrática. } \\ \text { Coexistence. } & \text { educacionais, } \\ \text { Between the } & \text { a alfabetização } \\ \text { Educational } & \text { escolar e a } \\ \text { Practices, the } & \text { aprendizagem na } \\ \text { School Literacy and } & \text { cidade }\end{array}$

Víctor Hugo Garcés* https://orcid.org/0000-0002-2185-5177 


\title{
Resumen
}

Escasos estudios han abordado la relación entre educación ciudadana y convivencia. No obstante, este artículo proporciona una descripción de la contribución de la educación democrática a la convivencia democrática. Para esta revisión se seleccionaron publicaciones indexadas que ofrecieron elementos para comprender la formación de convivencia ciudadana en Colombia. Los resultados del análisis arrojan tres grandes tendencias: (1) La consolidación de prácticas educativas resultantes de la pugna entre las políticas educativas y la concertación curricular de los maestros. (2) El diseño de programas de alfabetización de ciudadanos basados en el fomento de la interacción con el Estado y las maneras de interactuar en sociedad, el desarrollo de experiencias democráticas que diriman el conflicto multicultural e intercultural conviviendo en diversidad y el uso de problemas reales y simulacros para la discusión democrática y definición de iniciativas ciudadanas de participación y convivencia. (3) Reflexiones que proponen: comunicar la escuela con la maneras de practicar la cultura política y establecer los vínculos sociales que facilitan las tecnologías y los medios; articular la capacitación y participación escolarizada de la comunidad con la normatividad aprendida de la urbe y en la ciudad educadora; complementar la enseñanza moral y cívica con la deliberación y el encuentro con el otro en lugares de decisión; y, fortalecer, desde el aula, las competencias ciudadanas aprendidas en espacios participativos.

\author{
Palabras clave \\ educación; ciudadanía; educación ciudadana; disciplina escolar; \\ convivencia escolar; investigación sobre el currículo
}

\begin{abstract}
Scarce studies have addressed the relationship between citizenship education and coexistence. However, this article provides a description of the contribution of democratic education to democratic coexistence. For this review were selected indexed publications that offered elements to understand the training for citizenship coexistence in Colombia. The results of the analysis cast three big trends: (1) The consolidation of educational practices resulting from the struggle between educational policies and the teachers' curricular concertation. (2) The design of citizen literacy programs based on the encouragement of interaction with political institutions and the ways to interact in society, the development of democratic experiences that settle the multicultural and intercultural conflict living together in diversity and the use of real problems and drills for democratic discussion and definition of citizen initiatives of participation and coexistence. (3) Reflections that propose: communicate the school with the ways of practicing political culture and establish social bonds that technology and media facilitate; articulate the training and school participation of the community with the regulations learned from the city and the educating city; supplement moral and civic teaching with deliberation and meeting with the others in places of decision; and, strengthen, from the classroom, the civic competencies learned in participatory spaces.

Keywords

education; citizenship; citizenship education; school discipline; school coexistence; curriculum research
\end{abstract}

\section{Resumo}

Escasso estudos têm abordado a relação entre educação para a cidadania e convivência. Não obstante, este artigo fornece uma descrição da contribuição da educação democrática na convivência democrática. Para esta revisão foram selecionados publicações indexadas que ofereceram elementos para entender a formação da convivência cidadã na Colômbia. Os resultados da análise mostram três tendências principais: (1) A consolidação das práticas educativas resultantes da luta entre as políticas educacionais e o acordo curricular dos professores. (2) 0 desenho dos programas de alfabetização de cidadãos baseados na promoção da interação com o Estado e as formas de interagir na sociedade, o desenvolvimento de experiências democráticas que resolvem o conflito multicultural e intercultural vivendo juntos na diversidade e o uso de problemas reais e simulações para a discussão democrática e definição de iniciativas cidadãs de participação e convivência. (3) Reflexões que propõem: comunicar a escola com as formas de praticar a cultura política e estabelecer os laços sociais que as tecnologias e os meios de comunicação facilitam; articular a instrução e a participação escolar da comunidade com as normativas aprendidas da metrópole e em a cidade educadora; complementar o ensino moral e cívico com deliberação e o encontro com o outro em lugares de decisão; e, fortalecer, da sala de aula, as competências cívicas aprendidas nos espaços participativos.

\section{Palavras chave}

educação; cidadania; educação cidadã; disciplina escolar; convivência escolar; pesquisa sobre currículo 


\section{Introducción}

La relación entre educación ciudadana y la convivencia escolar en el ámbito de la educación se ha comprendido como dos fórmulas educativas diferenciadas y delimitadas, principalmente, a un problema pedagógico o didáctico. El conflicto y la violencia escolar, en tanto prácticas y procesos de interacción en el seno de la escuela, se han tratado como cualquier otro problema que trastoca la atención del estudiante, las condiciones de enseñanza y la posibilidad de desarrollo inclusivo, democrático y pacífico (Adams, 2000; Unesco, 2008; Osher et ál., 2010; Fierro, 2013; García y López 2014; Sáez, Figueroa y Pereira, 2018; Welsh y Little, 2018). Entre tanto, la educación ciudadana se ha entendido, pese a las novedosas corrientes que proponen la formación democrática mediante procesos deliberativos, participativos, multiculturales y divergentes (Sant, 2019), como un técnica didáctica que permite la transmisión de conocimientos sobre la instituciones y los procedimientos democráticos que habilitan al futuro ciudadano a participar en diferentes contextos políticos y a reflexionar y contribuir, de manera racional y crítica, a los problemas políticos y sociales de un modo de vida asociado (Abowitz y Harnish, 2006; Geboers et ál., 2013; Lin, 2013). Se ha reducido a la alfabetización ciudadana al proceso de enseñanza encargado de formar un ciudadano moral, conocedor de los derechos, las libertades y las responsabilidades, respetuoso de las normas y las leyes, que participa de la elección y la representación escolares a manera de aprender a relacionarse con el Estado y a interactuar democráticamente en la vida en comunidad (Uribe, 1996; Terrén, 2003; Pérez, 2007; Camps, 2007; Del Rey, Ortega y Feria, 2009; Sánchez, 2015).

Sin embargo, en los últimos decenios en Colombia, las innovadoras perspectivas de los estudios de la ciudadanía escolar generaron un cambio en la forma de comprender la escuela, que no solo ha permitido superar los abordajes didácticos de la ciudadanía y prácticos-controladores del conflicto escolar, sino que, también, ha admitido avanzar en la comprensión de la relación entre la ciudadanía y la convivencia. Es por esta razón que, para comprender este avance, se hizo necesario aproximarse hermenéuticamente desde los aportes de la investigación de la ciudadanía en la escuela a las trayectorias que trazan la experiencia colombiana en formación de convivencia ciudadana.

Para tal fin, a continuación, se describirá en un primer momento la reconstrucción interpretativa de los itinerarios que le dan forma a esta relación, tanto desde las luchas por el diseño de la política educativa como desde los ámbitos de la escolarización y su integración con la vivencia de la ciudad. Luego se finalizará con un balance reflexivo que permite interpretar la relación entre concepción de la escuela, investigación y formación en convivencia ciudadana.

\section{La disputa por el diseño de las políticas educativas de la formación de convivencia ciudadana en Colombia}

La formación ciudadana y convivencial en Colombia ha estado percibida por los diferentes gobiernos como una serie de mecanismos que hegemonizan al sujeto e instruyen valores cívicos desde su visión particular (Caballero, 2015). Cada grupo político que ha ostentado el poder a lo largo de la historia concibió e impulsó un enfoque de lo que debía ser el ciudadano, una imagen de cómo se llevaría a cabo la formación ciudadana y unas orientaciones de lo que convenía que fueran los proyectos de democracia en la escuela y la convivencia escolar.

Como reflejo de esta puja, la formación en convivencia ciudadana en Colombia comenzó por alternar entre las perspectivas impulsadas por el bipartidismo político. Bajo unos gobiernos se promovió la formación cívico-religiosa, que buscaba el impulso y la defensa de la doctrina católica, donde la cultura política estaba en estrecha relación con el virtuosismo del ideario cristiano; mientras que incentivada por otros periodos políticos fue impulsada la cultura cívica, que formaba en compromisos ciudadanos, conducentes a la participación y el alto grado de conocimiento del funcionamiento del sistema político (Sábato, 1997; Herrera et ál., 2005; Caballero, 2015). Desde el partido conservador se impulsaron los enfoques centrados principalmente en la persona, sus valores, su conocimiento y sus 
potencialidades; mientras que desde el partido liberal se promovieron rumbos más tendientes a las dinámicas sociales, la participación y la institucionalidad (Herrera, 2008; Caballero, 2015; Valencia, Cañón y Molina, 2012).

No obstante, con el tiempo, la formación de políticas educativas de convivencia ciudadana se convirtió en un campo de pugna, donde entraban en contradicción las exigencias internacionales y las demandas de los ciudadanos, en especial las del movimiento pedagógico (Guerra, 2008; Caballero, 2015). Los intereses gubernamentales comenzaron a poner en marcha la implementación de las políticas internacionales, mientras que el movimiento pedagógico integraba avances curriculares y mecanismos que democratizaban el diseño de la formación en ciudadanía y convivencia.

Si bien durante largo tiempo han primado los intereses promovidos por el proyecto gubernamental de turno, las innovadoras prácticas pedagógicas del movimiento magisterial, al integrar a la legislación educativa estrategias de democratización de la gestión del sistema escolar (Hurtado y Álvarez, 2006), lograron modificar sustancialmente las prácticas educativas (Caballero, 2015). Mecanismos como la elaboración y actualización periódica del Proyecto Educativo Institucional (PEI), la concertación democrática del manual de convivencia, la conformación de un gobierno escolar y la representación de estudiantes y maestros ante diferentes instancias administrativas (Caballero, 2015), permitieron una relación dialéctica, algo desequilibrada, entre las necesidades y exigencias contextuales y la implementación de políticas educativas predefinidas por expertos.

Resultado de esta puja, en los currículos oficiales de formación ciudadana se integraron competencias, se fortalecieron contenidos y se agregaron pruebas estandarizadas de los saberes ciudadanos. A la formación cívica, por un lado, se le lograron incluir elementos como "la formación en derechos o la idea de ciudadanía como responsabilidad individual" (Caballero, 2015, p. 113), los valores, principios, deberes, comportamientos y conocimientos necesa- rios para conocer y participar del funcionamiento del sistema político democrático, entre otros ajustes y reformas; por otro lado, se comenzaron a realizar evaluaciones estandarizadas, que pretendían hacer un balance de los logros y retos de la formación en ciudadanía y convivencia (Torres y Pinilla, 2005). Estas cuestionaban a los estudiantes sobre sus representaciones valorativas, sus relaciones con los demás, la manera de pensar y vivir la ciudad y la ciudadanía, las formas de razonamiento moral que esgrimen a la hora de tomar decisiones y el clima familiar y escolar donde se mueven (Pinilla y Torres, 2006; Caballero, 2015).

A esta política pública de homogenización, no solo se contrapusieron algunos movimientos sociales, de maestros y estudiantes, sino que al tiempo se dieron "prácticas pedagógicas y teorías educativas alternativas que cuestionaron dichos presupuestos" (Herrera e Infante, 2004, p. 80). Mientras que el movimiento pedagógico discutía los discursos y procedimientos contenidos en las políticas educativas, cada institución educativa, e incluso cada maestro, comenzó a interpretar y materializar estos lineamientos a su manera, cada aporte práctico comenzó a exigir nuevas maneras de comprender la educación en convivencia y ciudadanía.

De ahí que Guerra (2008) afirme que las exigencias del magisterio siguieron dos sentidos paralelos y complementarios: por una parte, el nivel macro, donde se promovía la lucha por el significante de los discursos teóricos y normativos de la regulación educativa; por la otra, el nivel micro, donde se resistía a la normalización, con maneras empíricas e innovadoras de resolver las formas de educar en ciudadanía y de construir la convivencia ciudadana. Mientras que se discutía la comprensión de los diferentes enfoques de democracia como significado de lo político $y$, en consecuencia, de su práctica ciudadana, se concebían formas prácticas, disímiles, de solucionar los conflictos y construir la convivencia ciudadana en la escuela.

Así, de un lado, en el nivel "Macro", la discusión sobre el contexto de la cultura democrática, que se debe vivir en la escuela, marcó el diseño de la 
política educativa de la formación política y convivencial. Desde los lineamientos, la política educativa colombiana insistía en concebir la democracia como procedimiento, que, en tanto que instrumental, debía dirimir las relaciones conflictivas, enseñar a ajustar a los sujetos al acatamiento y cumplimiento de normas, promover ciudadanos dóciles y sumisos que participaran de la política únicamente desde la representatividad y el ejercicio del voto. Por su parte, los movimientos pedagógicos exigían entender la democracia como régimen, instancias de decisión que instituía prácticas más allá de lo normativo, al tiempo que permitían dirimir las relaciones conflictivas de la sociedad y establecer formas de autogobierno; esto es, una serie de praxis democráticas, que resolverían los intereses antagónicos y que pondrían en marcha la capacidad de deliberación y decisión, la habilidad ciudadana de transformar las políticas y la posibilidad de instituir prácticas que permitan acceder a la autonomía efectiva, tanto en lo individual como en lo colectivo.

Simultáneamente, en el nivel "Micro", afirma Guerra (2008) que existen experiencias significativas que han modificado y reconstituido las prácticas tradicionales de la formación ciudadana y convivencial. Experiencias innovadoras que no se limitaban ni reducían al procedimiento del gobierno escolar y a las estrategias pedagógicas de eliminación de los conflictos escolares, culturales y epistemológicos, sino, por el contrario, eran prácticas educativas, de diferente índole, que se centraban en procesos de participación y deliberación pública; procesos educativos de resistencia que han fundado nuevas formas y maneras de abordar la administración, la organización política escolar, toda vez que han favorecido la emergencia de una nueva cultura de la ciudadanía y la convivencia. Aseguran Aguilar y Betancourt que las experiencias de maestros muestran tanto "formas creativas de participación como el autogobierno escolar, la proyección y vinculación de la escuela a los problemas y necesidades de su comunidad" (2000, p. 174) como el desarrollo de procesos que posibilitan asumir la convivencia cotidiana como objeto de reflexión y acción pedagógica, en el marco de la formación de la persona moral.

\section{Las apuestas escolares: de los contenidos a las prácticas de aprendizaje}

Además de las diferentes maneras de diseñar o influir en el diseño de una política educativa de la formación de convivencia ciudadana, son varias las trayectorias prácticas que la literatura sobre el tema sistematiza. La gran mayoría de estas construyen la síntesis de diferentes experiencias educativas, mientras que otras expresan rumbos e itinerarios que la formación en convivencia y ciudadanía puede transitar. Sin embargo, cada una comienza a trazar un enfoque diferenciado, pero en cierto sentido complementario, de la manera como la escuela colombiana afronta la tarea de formar convivencia ciudadana.

De ahí que una primera trayectoria práctica parta del balance de la tradicional forma de educar en convivencia ciudadana, para afirmar que esta, al igual que la educación en derechos humanos, se viene circunscribiendo "al aislamiento de las instituciones” (Ipazud, 2009, p. 82), al autodiseño descontextualizado de la instrucción cívica y convivencial. Se asegura, luego del análisis de diversas experiencias colombianas, que muchas instituciones educativas han solventado la formación de una cultura de la convivencia y la ciudadanía limitándose a las exigencias de las políticas educativas: reproducen la vieja instrucción cívica y la formación en valores, se apegan a las temáticas de la paz y la democracia, hacen énfasis en el gobierno escolar, o tematizan en diversidad de género, culturas, entre otras problemáticas sociales, pero omiten que el aprendizaje de la exigibilidad de los derechos y deberes ciudadanos y el reconocimiento del otro con el que convivimos es un elemento sustancial de la cultura pública cotidiana.

Se ha desconocido que la democracia y la convivencia escolar implica no solo inculcar saberes y prácticas, sino, también, posibilitar un mundo público fuerte. Promover la constitución de una convivencia pública efectiva que haga que, en el marco de la vida compartida de los ciudadanos, no se sea ajeno o indiferente con la diferencia. Una educación que garantice que los escenarios escolares, y públicos, de exclusión social, política y cultural, de marginación y confinamiento se superen, no solo 
con la instrucción de valores y prácticas ciudadanas y convivenciales, sino también, con la construcción, desde la universalización de los derechos humanos, de "una cultura pública cimentada en el reconocimiento del otro y en el respeto por las diferencias" (Ipazud, 2009, p. 80).

Por lo tanto, es menester de la formación en ciudadanía y convivencia generar una nueva cultura ciudadana y pública que materialice en las interacciones de las nuevas generaciones el derecho a ser diferente, no solo como reconocimiento de la expresión cultural, sino también como un mecanismo que integra los grupos sociales, desde sus diferentes experiencias y expectativas de la vida social (Young, 1996). Una educación cultural que, por un lado, garantice la enseñanza del reconocimiento normativo a ser diferente, en términos de etnia, raza y lengua, no solo debe reconocer los sujetos desde su disimilitud, sino también sus demandas legales, políticas o económicas, sin comprometer el derecho de pertenencia (Rosaldo, 1997); por el otro, que transmita los conocimientos y los procesos cognitivos necesarios para constituir sujetos ciudadanos interculturales, dialógicos, críticos, conscientes del cumplimiento de los deberes y la exigibilidad de los derechos humanos (tanto de sí mismos, como de los otros), de las formas en que se participa del sistema estatal y de la manera de interactuar en sociedad.

Para otra trayectoria "estar juntos" necesita que se creen puentes epistemológicos y experienciales (Dietz, 2012), que vayan más allá de la enseñanza actitudes y valores convivenciales, que produzcan reconocimiento real de la alteridad ciudadana y de la diversidad de visiones de mundo (Samoná, 2005; Skliar, 2012). No solo porque se puede conocer la alteridad ciudadana, sino porque en ambientes de aprendizaje se vive, se apropia, se experimenta; se viene al mundo como ciudadano, en el seno de la colectividad, mientras que la forma particular de percibir y entender la realidad (la subjetividad individual), en su dialéctica educativa con el otro significante (el otro cultural o el otro educador), acoge o no la convivencia (Muñoz, Gamboa y Urbina, 2014).
Por ello, la cuestión de estar en un espacio propio y estar juntos en un escenario colectivo debe permear los contenidos y las prácticas escolares. Se debe generar una enseñanza que transforme las estructuras cognitivas, valorativas, estéticas, discursivas y las formas de razonamiento discriminatorio (Muñoz, Gamboa y Urbina, 2014); así como una serie de prácticas escolares que promuevan la vivencia de escenarios interculturales. Una educación donde se aprenda del otro y se conviva con el otro.

Una educación ciudadana y convivencial que parta del reconocimiento del conflicto intercultural, no necesariamente étnico, que genera negociación entre cosmovisiones (Bogoya y Santana, 2013), que permita "la afectación del otro y de sí mismo, pero que el otro siga siendo el otro" (Muñoz, Gamboa y Urbina, 2014, p. 24). Un diseño curricular de la formación en convivencia y ciudadanía que responda al problema de la alteridad cultural, desde la promoción de un diálogo intercultural y que no se funde en la discriminación positiva, el acceso y respeto del otro, sino en la construcción de un nosotros intercultural.

No obstante, desde una tercera trayectoria se afirma que se debe formular una educación en convivencia ciudadana que enseñe, tanto desde los contenidos como desde las prácticas, la resolución de conflictos políticos comunitarios y culturales. No solo se afirma que se deben trazar diseños curriculares significativos, relevantes y pertinentes con el contexto, también se debe proyectar la adquisición de herramientas conceptuales que permitan participar de la dimensión política de la institución, deliberar sobre las diferencias socioculturales y promover escenarios interculturales que faciliten el aprender a pensar, a ser y actuar en paz.

Se afirma, en efecto, que la convivencia ciudadana no solo debe emerger de la enseñanza y recreación de contenidos oportunos a la construcción o estímulo a los procesos cognitivos y comunicativos, sino debe alimentarse del diseño de un espacio para la discusión y la definición de iniciativas ciudadanas (Bogoya y Santana, 2013). Se debe impartir una formación en valores ciudadanos, democráticos 
y convivenciales que, mediante el análisis de problemas reales, logre desarrollar conocimientos sólidos que puedan ser asimilados y utilizados en la práctica de la convivencia ciudadana cotidiana (Bogoya y Santana, 2013, p. 26). En los contenidos impartidos deben existir problemas que resolver, y en las prácticas, simulacros de las situaciones problémicas, de tal manera que el educando apropie capacidades que le sirvan para solucionar sus conflictos cotidianos.

Una última trayectoria asegura que las instituciones educativas se deben reconocer como espacios aptos para vivir y practicar la democracia y los valores que atestiguan la convivencia (Puig y Morales, 2010). En la escuela pueden existir marcos de la experiencia escolar que, a través de las rutinas escolares, las interacciones interpersonales, las oportunidades de desarrollo de capacidades y las experiencias modeladoras transformen el sentir, el pensar y el actuar de los alumnos; proyectos transversales y procesos de tramitación escolar que permitan la vivencia y la apropiación de la forma de vida y de gobierno democrático.

Esas experiencias pueden ser los diversos espacios de prevención, mediación e intervención de la violencia; los encuentros para la participación, deliberación y definición de las normas de convivencia, áulicas y escolares; las instancias de conciliación y resolución de conflictos, que pretenden garantizar un clima de convivencia ciudadana (Bisquerra, 2008). Al tiempo que mecanismos de participación ciudadana como el colegiado escolar, las constituyentes escolares, las plenarias pedagógicas y la democratización interna de la gestión y la planeación administrativa y curricular, instancias donde toda la comunidad académica tiene la oportunidad de participar y reflexionar el programa educativo y cultural de la escuela ciudadana (Rodríguez, 1997).

\section{Trayectorias extraescolares: apuestas por la articulación entre la escuela y la ciudad}

Otra trayectoria propone que la educación en convivencia y ciudadanía necesita, en una primera instancia, que la escuela se transforme, de tal manera que se pueda comunicar a través de la interacción mediática con el contexto. Para hacer más efectiva la formación en convivencia ciudadana, los procesos de enseñanza-aprendizaje tendrían que adaptarse a las nuevas maneras de practicar la cultura política y establecer los vínculos sociales. Se tendría que comunicar el sistema escolar, sus procesos y efectos con los campos de experiencia ciudadana extraescolar, como manera de comprender y actuar en las nuevas formas de habitar la ciudad y de establecer vínculos culturales y políticos (Martín, 2004).

De ahí que una primera trayectoria que relaciona la escuela y la ciudad parta de afirmar que como hoy en día una gran parte de la formación y las prácticas de la diferencia, la convivencia y la participación política urbana pasan por el uso de los medios y las nuevas tecnologías. La escuela debería "formar para" y "articularse con" estos nuevos campos de la experiencia convivencial y ciudadana. Los procesos escolares de formación de convivencia ciudadana no solo deberían cambiar el modelo comunicativo/ pedagógico vertical y autoritario (Kaplún, 1998) por prácticas educativas que asuman la disidencia y la diferencia como claves de discusión y concertación política, sino que deberían enseñar a leer ciudadanamente el mundo desde una mentalidad crítica, cuestionadora y desajustadora, que haga que los sujetos piensen por sí mismos y no por las ideas que circulan en los ecosistemas mediáticos (Martín, 2004). Al mismo tiempo que deberían enseñar a producir e interactuar con la tecnicidad mediática, como posibilidad de participación del ámbito de la política y del establecimiento de una convivencia en paz.

Mientras que otra trayectoria afirma que la escuela, en su diálogo con la ciudad, se debería transformar en un nuevo territorio de la construcción de ciudadanía y convivencia de las diferencias (Gadotti, 2005). Por un lado, le incumbiría brindar proyectos de capacitación ciudadana y experiencias prácticas innovadoras que ratifiquen los principios de la vida civilizada. Transformarse en una escuela que educa, "para oír y respetar las diferencias, la diversidad que caracteriza la ciudad y que se constituye en su gran riqueza" (Gadotti, 2005, p. 58). Y, por el otro, sería su obligación crear mecanismos para la democratización 
dela gestión y la planeación participativa del currículo, espacios de participación ciudadana, como el colegiado escolar, la constituyente escolar, las plenarias pedagógicas, entre otros, que permitan llevar al interior de la escuela los intereses y necesidades de los sujetos de la ciudad donde se instala.

Entre tanto, la escuela ciudadana dialogaría con la ciudad que educa desde su papel orientador e integrador de la convivencia y la participación ciudadana extraescolar. Los ciudadanos no solo aprenderían a partir de vivir y explorar la metrópolis, reconocer y desaprobar su entorno cultural, así como juzgar moralmente las acciones ilegales y los actos de corrupción (Mockus, 2001), o a través de la creación y apropiación de normas y acuerdos convivenciales y funcionales que regulen las relaciones entre las personas, la infraestructura y los servicios urbanos (Moncada, 2015), sino que integrarían estos aprendizajes a la escuela para crear nuevas relaciones sociales, humanas e intersubjetivas. Simultáneamente, el ciudadano aprendería, desde las experiencias democrática escolar, a construir una ciudadanía plena y activa, a apropiar la ciudad y a influir en la configuración de la urbe y en la forma de vivir en ella (Trilla, 2015), complementaría lo aprendido con nuevos estímulos y prácticas políticas ofrecidas por la ciudad educadora (Trilla, 1997).

Así, el ciudadano escolarizado aprendería una nueva cultura política urbana. Progresivamente, los estudiantes reapropiarían culturalmente la ciudad (la necesidad de educar, de aprender, de enseñar, de conocer, de crear, de usufructuar la ciudad) y romperían con el control político de las élites al establecer, desde la convivencia democrática escolar, una nueva esfera pública de decisión no estatal (Gadotti, 2005). Al tiempo que asimilarían en su relación con la red cívica, cultural y comercial las nociones del mundo civilizado, las formas de comportarse en la densidad de los encuentros urbano y el uso cotidiano de los objetos y los servicios metropolitanos. Aprenderían de "la ciudad como entorno o contenedor de educación (aprender en la ciudad), como fuente o agente educativo (aprender de la ciudad), y como objetivo o contenido de la educación (aprender la ciudad)" (Trilla, 1997, p. 7).
Para otra trayectoria, la educación en ciudadanía y convivencia se debería impartir desde la relación formativa existente entre el ámbito académico escolarizado y los espacios institucionales de participación ciudadana. Pues, se asegura que, desde la integración de los currículos escolares con los ambientes de aprendizaje urbano se producirían los cambios necesarios para que se dé una transformación de la manera de pensar, ser, actuar y convivir del ciudadano.

De ahí que se proponga que los estudiantes deban vivir en el aula la dotación de competencias y destrezas de convivencia social, para que en una segunda instancia, que podría ser simultánea, realicen una "estancia investigativa" de contexto, en los espacios, institucionales o no, de participación ciudadana (Rodríguez, 1997; Huertas, 2016). Primero, se desarrollarían habilidades, relacionadas con la ética, la civilidad, la buena convivencia, el equilibrio, la armonía social y el desarrollo de las implicaciones "tanto del aprendizaje de la doctrina, como el debate de las brechas, los conflictos, y las ambigüedades de la doctrina" (Kennedy, 2012 citado por Huertas, 2016, p. 127); para que, posteriormente, desde la experiencia práctica, se complementaran con: la visibilización de los principales rompimientos entre la situación de violencia política y el Estado; la apropiación de herramientas para la defensa de los ciudadanos; la concepción de los principales retos de la ciudad y la cualificación de las estrategias de comunicación social.

De esta manera, la combinación de la instrucción y la praxis ciudadana y la convivencia desde el ámbito escolar hacia los espacios participativos de la ciudad desarrollarían "nuevas formas de pensar, y actuar, de manera que derivarían nuevas formas de tomar, abordar y comprender las relaciones entre las personas en todos los campos en los que pudiera desenvolverse el ser humano" (Huertas, 2016, p. 127). En ambos procesos se generarían cambios culturales dirigidos hacia la conciliación y la concordia en pro de la convivencia ciudadana. Transformaciones culturales que derivarían de la reflexión conceptual de la complejidad social, el ejercicio de los conflictos sociales, las vulneraciones 
individuales y las precariedades de las perceptivas, simultáneamente que, de las discusiones, los conflictos y las situaciones de crisis del contexto experimentadas en los espacios, escolares y extraescolares, de praxis ciudadana y convivencial (Huertas, 2016).

Una última trayectoria afirma que la convivencia ciudadana se aprendería al ejercer cotidianamente la inteligencia práctica, o razón política práctica, en los escenarios educativos y comunitarios de la ciudad, mientras que se afina y se potencia en los ámbitos escolares mediante la participación en la deliberación y el juicio, en el acto de elegir y optar, en el marco de la pluralidad y la diversidad comunitaria (tanto de perspectivas como de propuestas y grupos sociales). Se extiende desde las prácticas de aprendizaje de la ciudad educadora hasta el ámbito de formación ciudadana de la escolarización, se ejercerían y consolidarían las virtudes cívicas, la ética del servicio a la comunidad y la práctica de la participación, la deliberación y la justicia.

Para este itinerario, la formación ciudadana fáctica, o educación política, se aprendería en el hecho de construir juntos, de convivir en la diferencia y de transformar la sociedad. Una formación de una inteligencia práctica en la ciudadanía que se construiría en el hacer con el otro. Los sujetos, adquirirían las competencias cognitivas y vivirían los simulacros de gobierno y de la vida democrática en la convivencia escolar. Al tiempo que se encontrarían, deliberarían y decidirían en los espacios de participación y educación ciudadana; se informarían y opinarían; consumirían y producirían campañas de sensibilización en derechos humanos y vida en paz; interactuarían con el Estado y construirían y alcanzarían, con su ejercicio, metas afines con los objetivos comunes de la ciudadanía.

Se afirma, entonces, que la educación en convivencia ciudadana se debería centrar en el desarrollo de la capacidad de organización colectiva o, lo que es lo mismo, en el protagonismo del compromiso que el ciudadano tiene en la consecución de una convivencia pacífica y crítica en toda la sociedad (Gómez y Cabrera, 2005). Pues, esta identidad cívica permitiría construir nexos de solidaridad, altos niveles de confianza y capacidades comunicativas, dialógicas y de disfrute social; así como sería útil para aclarar diferencias, dirimir conflictos y celebrar acuerdos cotidianos, tanto en el ámbito escolar como en el extraescolar.

\section{A modo de conclusión: escuela, investigación y convivencia ciudadana}

Lo expuesto a lo largo de este artículo da una aproximación a las trayectorias recorridas al momento de abordar la educación en ciudadanía y convivencia. Durante los diferentes apartados, cada trayectoria se identificó un marco teórico y práctico de la relación entre la formación en convivencia y ciudadanía, las prácticas, reales y posibles de esta. Lo cual trazó abordajes distintos, pero en cierta medida complementarios, del objeto de investigación aquí expuesto.

Sin embargo, con un análisis más detallado se podría afirmar que una determinada concepción de la escuela desencadenaría en un marco de abordaje investigativo y práctico de la formación en convivencia y ciudadanía. Así, si se comprende la escuela como una gramática de procesos dispuestos para la transmisión de conocimientos, virtudes y modos de actuar (predeterminados, ideales, verdaderos y validados), se hace hincapié en una instrucción cívica, cuyos problemas investigativos girarían en torno a la cuestión didáctica y a los modos de control y resolución del conflicto, en tanto que ruido del proceso educativo. Sí se comprende el currículo y la organización escolar como resultante de la pugna histórica entre la implementación de políticas educativas y las resistencia y apuestas innovadoras de los movimientos pedagógicos, las prácticas educativas en convivencia ciudadana serían la resultante fáctica de la puja por la escuela como espacio social de la política; en efecto, desencadenaría en indagación histórica de los cambios, normativos, curriculares y prácticos in situ, imprimidos por las resultantes de estas luchas.

Del mismo modo, si se entiende la escuela como una estructura de reproducción social que actúa sobre la comunidad (en tanto contenedora de la diferencia, el conflicto y la otredad), el currículo y 
los espacios escolares se convierten en objetos de diseño y gestión de las mejores maneras de aprender, ejercitar y apropiar la convivencia y la ciudadanía; mientras que la investigación se centraría en reconocer, desde sus apuestas prácticas, los aciertos y desacierto de las experiencias educativas. Finalmente, si se comprende la escuela como parte de la comunidad, se buscará darle sentido en su articulación con el contexto, bien sea para adaptarla o abrirla a las dinámicas sociales que le circundan, $\mathrm{o}$ articulándola con otros espacio de convivencia ciudadana y participación política, impulsados por políticas urbanas de construcción de cultura ciudadana; lo que, en efecto, desplazaría la indagación a la valoración de los periodos de articulación entre las políticas urbanas de formación en convivencia ciudadana y las estrategias escolares de articulación con la ciudad que educa.

Sin lugar a duda, este balance de las trayectorias en las que se ha abordado la formación en convivencia y ciudadanía en Colombia muestra que, a pesar de las diferencias teóricas en cuanto al abordaje conceptual e investigativo (Garcés, 2020), es posible construir un macroproyecto pedagógico que actúe desde diferentes estrategias educativas. La articulación resultante de un trabajo juicioso de adaptación y ensamblaje de los diferentes enfoques, podrían marcar la pauta para materializar una innovadora educación en convivencia y ciudadanía. Un diseño curricular y experiencial que, combinando los disímiles ámbitos escolares y extraescolares, se dirigiera al cambio en las maneras de pensar, ser y actuar en contextos de conflicto, de diferencia, de otredad y de participación. Una educación en ciudadanía y convivencia que, desde múltiples vivencias de aprendizaje, lograría una comunidad democrática, participativa, crítica y deliberante, que se extienda más allá del escenario escolar.

\section{Referencias}

Abowitz, K. y Harnish, J. (2006). Contemporary Discourses of Citizenship. Review of Educational Research, 76(4), 653-690. https://doi.org/10.3102/ 00346543076004653
Adams, A. (2000). The Status of School Discipline and Violence. The ANNALS of the American Academy of Political and Social Science, 567(1), 140-156. https:// doi.org/10.1177/000271620056700110

Aguilar, J., y Betancourt, J. (2000). Construcción de cultura democrática en instituciones educativas de Santafé de Bogotá. Instituto para la Investigación Educativa y el Desarrollo Pedagógico-IDEP; Innova editorial.

Bisquerra, R. (2008). Educación para la ciudadanía y convivencia. El enfoque de la Educación Emocional. Wolters Kluwer España S.A.

Bogoya, N. y Santana, C. (2013). Hacia una pedagogía para la ciudadanía. Infancias Imágenes, 5(1), 24-27. https://revistas.udistrital.edu.co/index.php/ infancias/article/view/4540

Caballero, L. (2015). La formación ciudadana en la "Bogotá Humana" (2012-2014) en el contexto de las políticas públicas nacionales de educación. Ciudad Paz-ando, 8(2), 101-123. https://revistas.udistrital. edu.co/index.php/cpaz/article/view/10290

Camps, V. (2007). Educar para la ciudadanía. Fundación ECOEM.

Del Rey, R., Ortega, R. y Feria, I. (2009). Convivencia escolar: fortaleza de la comunidad educativa y protección ante la conflictividad escolar. Revista interuniversitaria de formación del profesorado, (66), 159-180.

Dietz, G. (2012). Reflexividad y diálogo en etnografía colaborativa: el acompañamiento etnográfico de una institución educativa "intercultural" mexicana. Revista de Antropología social, 21, 63-91. https://doi. org/10.5209/rev_RASO.2012.v21.40050

Fierro, M. (2013). Convivencia inclusiva y democrática. Una perspectiva para gestionar la seguridad escolar. Sinéctica, Revista Electrónica de Educación, (40), 1-18. https://sinectica.iteso.mx/index.php/SINECTICA/ article/view/47

Gadotti, M. (2005). La escuela en la ciudad que educa. Educación y Ciudad, (8), 47-60. https://revistas. idep.edu.co/index.php/educacion-y-ciudad/article/ view/210

Garcés, V. H. (2020). Alfabetizar en convivencia y ciudadanía. Una revisión documental de la educación ciudadana para la resolución de la violencia y el conflicto sociocultural. Sophia, 16(1), 4-18. https:// doi.org/10.18634/sophiaj.16v.1i.874 
García, L. y López, R. (2014). La convivencia escolar y la construcción de la ciudadanía: balance retrospectivo y desafíos de futuro. Bordón. Revista de pedagogía, 66(2), 93-106. https://recyt.fecyt.es/index.php/ BORDON/article/view/Bordon.2014.66206

Geboers, E., Geijsel, F., Admiraal, W. y Dam, G. (2013). Review of the effects of citizenship education. Educational Research Review, 9, 158-173. https:// doi.org/10.1016/j.edurev.2012.02.001

Gómez, J. y Cabrera, M. (2005). Las competencias ciudadanas en el contexto de Bogotá como ciudad educadora. Enunciación, 10(1), 40-46. https://revistas. udistrital.edu.co/index.php/enunc/article/view/451

Guerra, L. (2008). Prácticas democráticas en la escuela. Ciudad paz-ando, 1(1), 33-44. https://revistas. udistrital.edu.co/index.php/cpaz/article/view/7423

Herrera, M. (2008). Esbozos históricos sobre cultura política y formación ciudadana en Colombia: actores, sujetos y escenarios. Universidad Pedagógica Nacional-Colciencias.

Herrera, M. e Infante, R. (2004) Las políticas públicas y su impacto en el sistema educativo colombiano. Una mirada desde los planes de desarrollo 1970-2002. Revista Nómadas, (20), 76-85. http://nomadas.ucentral.edu.co/nomadas/pdf/nomadas_20/20_7HI_ Laspoliticaspublicas.PDF

Herrera, M., Pinilla, A., Díaz, C. e Infante, R. (2005). La construcción de cultura política en Colombia: proyectos hegemónicos y resistencias culturales. Universidad Pedagógica Nacional.

Huertas, O. (2016). Incidencia de la educación desde un paradigma complejo en la formación de ciudadanos/ as. Ciudad Paz-ando, 8(2), 125-139. https://doi. org/10.14483/udistrital.jour.cpaz.2015.2.a07

Hurtado, D. y Álvarez, D. (2006). La formación de ciudadanías en contextos conflictivos. Estudios políticos, (29), 81-96. https://revistas.udea.edu.co/index.php/ estudiospoliticos/article/view/1297

Ipazud. (2009). Derechos y Deberes Ciudadanos: entre la ciudad y la escuela. Ciudad paz-ando, 2(2), 79-98. https://revistas.udistrital.edu.co/index.php/cpaz/ article/view/7376

Kaplún, M. (1998). Una pedagogía de la comunicación. Ediciones de la Torre.

Lin, A. (2013). Citizenship education in American schools and its role in developing civic engagement: a review of the research. Educational Review, 67(1), 35-63. https:// doi.org/10.1080/00131911.2013.813440
Martín, J. (2004). Una escuela ciudadana para una ciudad-escuela. Revista Educación y Ciudad, (6), 97-124. https://issuu.com/idep/docs/educacionyciudad6

Mockus, A. (2001). Divorcio entre ley, moral y cultura. Magazín Aula Urbana, (32), 12-13. https://revistas. idep.edu.co/index.php/mau/article/view/1176

Moncada, R. (2015). Ciudad, educación y escuela. Educación y ciudad, (7), 33-72. https://issuu.com/ idep/docs/educacionyciudad7

Muñoz, P., Gamboa, A. y Urbina, J. (2014). Deberes ciudadanos y diversidad cultural: comprensión de los discursos de estudiantes y docentes desde la alteridad y la subjetividad. Infancias imágenes, 13(2), 23-32. https://doi.org/10.14483/udistrital.jour. infimg.2014.2.a02

Osher, D., Bear, G., Sprague, J. y Doyle, W. (2010). How Can We Improve School Discipline? Educational Researcher, 39(1), 48-58. https://doi. org/10.3102/0013189X09357618

Pérez, R. (2007). Educación, ciudadanía y convivencia. Diversidad y sentido social de la educación. Bordón. Revista de pedagogía, 59(2), 239-260. https://recyt. fecyt.es/index.php/BORDON/article/view/36508

Pinilla, A., y Torres, J. (2006). De la educación para la democracia a la formación ciudadana, una década de incertidumbres. Universidad Pedagógica Nacional-IDEP.

Puig, My Morales, J. (2010). Los proyectos de innovación educativa y el desarrollo de la educación para la ciudadanía. Infancias imágenes, 9(1), 29-39. https:// revistas.udistrital.edu.co/index.php/infancias/ article/view/4479

Rodríguez, M. (1997). La escuela: primer espacio de actuación pública del niño. Educación y ciudad, (3), 8-19. https://revistas.idep.edu.co/index.php/ educacion-y-ciudad/article/view/247

Rosaldo, R. (1997). Ciudadanía cultural y minorías latinas en los Estados Unidos. En R. Winocur (coord.), Culturas políticas a fin de siglo (pp.243-265). Juan Pablos Editor.

Samoná, L. (2005). Diferencia y alteridad. Akal.

Sant, E. (2019). Democratic education: a theoretical review (2006-2017). Review of Educational Research, 89(5), 655-696. https://doi.org/10.3102/ 0034654319862493

Sábato, H. (1997). Ciudadanía política y formación de las naciones: perspectivas históricas de América Latina. Fondo de Cultura Económica. 
Sáez, D., Figueroa, O. y Pereira, S. (2018). Convivencia escolar para la ciudadanía a la luz de las dimensiones declaradas por la Unesco: percepción de los estudiantes de segundo ciclo. Revista Boletín Redipe, 7(2), 94-103. https://revista.redipe.org/index.php/1/ article/view/431/0

Sánchez, S. (2015). Educar para la ciudadanía. Seguridad, inclusión y convivencia en la educación básica en México del siglo xxi. Revista Latinoamericana de Estudios Educativos (México), 45(3), 55-80. https:// biblat.unam.mx/es/revista/revista-latinoamericana-de-estudios-educativos/articulo/educar-para-la-ciudadania-seguridad-inclusion-y-convivencia-en-la-educacion-basica-en-mexico-del-siglo-xxi

Skliar, C. (2012). El presente educativo en tanto comunidad existente: sobre el estar-juntos en las instituciones educativas. En J. Barragán, A. Gamboa y J. Urbina (Comp.), Práctica pedagógica. Perspectivas teóricas (pp. 3-17). Ecoe Ediciones.

Terrén, E. (2003). Educación democrática y ciudadanía multicultural: el reaprendizaje de la convivencia. Praxis, (3), 5-28.

Torres, J. y Pinilla, A. (2005). Las vías de la educación ciudadana en Colombia. Revista Folios, (21), 47-64. https://doi.org/10.17227/01234870.21folios47.64

Trilla, J. (1997). La educación y la ciudad. Revista Educación Y Ciudad, (2), 6-19. https://revistas.idep.edu.co/index. php/educacion-y-ciudad/article/view/256
Trilla, J. (2015). La idea de ciudad educadora y escuela. Educación y Ciudad, (7), 73-106. https://issuu.com/ idep/docs/educacionyciudad7

Unesco. (2008). Convivencia democrática, inclusión y cultura de paz: Lecciones desde la práctica educativa innovadora en América Latina. Organización de las Naciones Unidas para la Educación, la Ciencia y la Cultura (Unesco): http://unesdoc.unesco.org/ images/0016/001621/162184s.pdf

Uribe, M. (1996). Proceso histórico de la configuración de la ciudadanía en Colombia. Estudios políticos, (09), 67-76. https://revistas.udea.edu.co/index.php/ estudiospoliticos/article/view/16074

Valencia, G., Cañón, L y Molina, C. (2012). Educación cívica y civilidad: una tensión más allá de los términos. Pedagogía y Saberes, (30), 81-90. https://doi.org /10.17227/01212494.30pys81.90

Welsh, R. y Little, S. (2018). The School Discipline Dilemma: A Comprehensive Review of Disparities and Alternative Approaches. Review of Educational Research, 88(5), 752-794. https://doi.org/ $10.3102 / 0034654318791582$

Young, I. (1996). Vida política y diferencia de grupos: una crítica del ideal de ciudadanía universal. En C. Castells (comp.), Perspectivas feministas en teoría política (pp. 99-126). Paidós. 